\title{
"PEER PIRACY": aspectos centrais da produção por pares e da pirataria e suas contribuições nas transições do capitalismo contemporâneo
}

\author{
José Carlos Messias Santos Franco \\ Doutorando em Comunicação pela Universidade Federal do Rio de Janeiro (UFRJ).
}

\begin{abstract}
Resumo
Não há dúvidas de que a pirataria digital contemporânea é produzida coletivamente por “peers", no entanto, o título deste artigo não diz respeito apenas às características da pirataria em si - embora elas devam ser retomadas em algum ponto. A escolha de "Peer Piracy" como título denota uma intenção de tratar dos atributos particulares dessas duas formas de apropriação cultural à luz da filosofia política, especialmente os trabalhos de Michel Foucault, Gilles Deleuze, Antonio Negri e Michael Hardt. Entendendo que essas são práticas opostas, ou pelo menos contraditórias entre si, do ponto de vista econômico/legal (e talvez ético), esse artigo não pretende juntálas ou realizar um estudo sobre seu entrelaçamento histórico e político. Pelo contrário, busca-se apontar como essas práticas marcam uma fase de transição do capitalismo global, e, acredita-se, estariam contribuindo, em suas singularidades e oposições, para construção de uma nova constituição econômica, política, social e cultural do presente.
\end{abstract}

Palavras-chave

P2P. Pirataria. Capitalismo cognitivo.

\section{"Peer Piracy": central aspects of peer production and piracy and their contributions to contemporary capitalism}

\begin{abstract}
Amidst the many political themes surrounding our contemporary age, one that draws more attention concerns the philosophical and legal discussion about property, especially (but not restricted to) intellectual property and copyright. Actually, it would be no exaggeration to say that the notion of private property as a whole is changing and that this transformations leads also to socio-economical, political and cultural consequences. In Digital Culture - one of the main poles of this scenario in dispute - the hacker and peer-to-peer (P2P) movements can be highlighted as two preponderant elements in the conceptual and quite physical taken of property. Nevertheless, it is necessary to inform that this paper does not intend to advocate in favor of this or that cause, but to show how this is a contemporary situation that must be an object of study in academia. In this sense, the Occupy movements, open software, collaborative economies and hacker groups (such as Anonymous) can be used as examples of the penetration of this thematic in our days. However, they must not be considered isolated cases of insurgency against the capitalist system and its means of production, but as manifestations of a structural change, a status quo modification, in the actual idea of property and its usage. Regarding hacker culture, the reference to our investigation will be a set of works commonly related with the so called cognitive capitalism and its respective influences, largely the French political philosophy. In the case of peer production, beyond the already mentioned bibliography, some authors such as Bauwens et al. were chosen in an attempt to establish a more integrative counterpoint to this cultural and consumption logics. Contemporary digital piracy is obviously peer-based yet the title of this short essay does not regard the characteristics of piracy in itselfalthough they will be addressed at some point. The choice for "peer piracy" as the title marks our intention to speak about the particular attributes of these two kinds of cultural appropriation. Understanding that these are opposed or at least contradictory practices in an economical/legal point of view, this paper intends not to mingle them together or study how they would be intertwined historically or politically. On the contrary, we seek to indicate how each one of them, in their own singularities, may be used to build a new economical, political and social constitution of the present. Thus, as a way to situate the debate inside this theoretical background, first it is necessary a short summary about what this essay understands for cognitive capitalism and how this conceptual operative fits in the socio-economical transitions of the last 30/40 years.
\end{abstract}

Keywords

P2P. Piracy. Cognitive capitalism. 


\section{INTRODUÇÃO}

Em meio à torrente de temáticas políticas que estão em voga, na contemporaneidade, uma das que mais chama atenção diz respeito aos debates (filosóficos e legais) sobre a propriedade, sobretudo (mas não restrita apenas) a propriedade intelectual e o direito autoral. À bem da verdade, não seria nenhum exagero afirmar que a noção de propriedade privada, como um todo, está mudando e que essas transformações acarretam também consequências socioeconômicas, políticas e culturais. Em meio à cultura digital - um dos principais polos desse cenário em disputa - a cultura hacker e o movimento peer-to-peer $(\mathrm{P} 2 \mathrm{P})$ podem ser destacados como dois elementos preponderantes nessa tomada conceitual e física da propriedade.

Em primeiro lugar, contudo, é preciso salientar que não é função deste trabalho advogar em função de uma causa ou de outra, mas mostrar como esse fenômeno que deve ser objeto de escrutínio da academia. Neste sentido, movimentos de ocupação (Occupy), software livre, economias colaborativas e coletivos hackers (como o Anonymous) podem ser citados como exemplos da pregnância deste tema na atualidade. Essa não é apenas uma questão de casos isolados de insurgência contra o sistema capitalista e seu modo de produção, mas se tratam de manifestações de uma mudança de ordem estrutural, uma alteração do status quo, no que se refere à própria ideia de propriedade e seus usos.

No tocante à cultura hacker, toma-se como referência um conjunto de obras inscritas dentro do chamado capitalismo cognitivo e suas respectivas influências, especificamente, a filosofia política francesa. Já no que se refere à produção por pares (peer production) evocase, além da já referida bibliografia, alguns autores selecionados como Bauwens et al., numa tentativa de estabelecer um contraponto mais integrador a essas lógicas culturais e de consumo.

Não há duvidas de que a pirataria digital contemporânea é produzida coletivamente por peers, no entanto, o título deste artigo não diz respeito apenas às características da pirataria em si - embora elas devam ser retomadas em algum ponto. A escolha de Peer Piracy como título denota uma intenção de tratar dos atributos particulares dessas duas formas de apropriação cultural.

Entendendo que essas são práticas opostas, ou pelo menos contraditórias entre si, do ponto de vista econômico/legal (e talvez ético), esse artigo não pretende juntá-las ou realizar um estudo sobre seu entrelaçamento histórico e político. Pelo contrário, busca-se apontar como essas práticas, individualmente, marcam uma fase de transição do capitalismo global e, 
"Peer piracy": aspectos centrais da produção por pares e da pirataria e suas contribuições nas transições do capitalismo

acredita-se, estariam contribuindo dentro de suas singularidades, para construção de uma nova constituição econômica, política, social e cultural do presente.

Assim, como forma de situar a discussão dentro de um arcabouço teórico, faz-se necessário um breve resumo sobre o que se entende por capitalismo cognitivo e como esse operativo conceitual se encaixa nas transformações socioeconômicas dos últimos 30/40 anos.

\section{Ownership is dead}

Embora não seja cognitivo no sentido estrito das neurociências, essa vertente do capitalismo foi batizada desta forma por conta do aspecto central da informatização (cibernética e processamento de dados), dos afetos e das sociabilidades na constituição dos modos de produção na atualidade. Dessa forma, dizer que o capitalismo das últimas décadas seria cognitivo, significa referenciar o caráter imaterial ou intangível de suas relações de sujeição para além de critérios puramente econômicos. Isso não significa dizer, no entanto, que o trabalho - instrumento do capital para obtenção do valor - tenha deixado de ser físico, braçal ou manual, mas que há uma diferença de ordem qualitativa nas dinâmicas do capital e de sua natureza sem que isso acarrete, necessariamente, numa redução do trabalho industrial/fabril e agrícola (NEGRI; HARDT, 2005, 2010).

Daí o surgimento também da expressão trabalho imaterial como forma de demarcar as mudanças nas formas de sujeição dentro desse campo. Da mesma forma que a industrialização promoveu uma serie de transformações estruturais (tanto físicas como metodológicas e culturais), inaugurando a Modernidade com a linha de montagem e a organização racional do trabalho, a informatização teria trazido o capitalismo a uma nova era: das finanças ao invés das fábricas, dos serviços ao invés dos produtos. Entretanto, isso não ocorreria como substituição quantitativa, mas como pensamento hegemônico. A esse cenário aparentemente paradoxal, de hegemonia não numérica e trabalho, ao mesmo tempo imaterial e material, autores como Matteo Pasquinelli nomearam capitalismo cognitivo. Para ele:

[...] quando falamos sobre capitalismo cognitivo ou sobre a hegemonia do trabalho imaterial, não nos referimos a algo 'imaterial', mas a um entrelaçamento maquínico bastante físico entre nossos próprios corpos e as relações sociais (PASQUINELLI, 2011, p. 16, grifos do autor e tradução nossa ${ }^{1}$ ).

Esse corpo a que Pasquinelli se refere pode ser tomado, num sentido amplo, como aquele inicialmente explorado por Michel Foucault quando discutiu suas noções de biopoder e

\footnotetext{
${ }^{1}$ Do original: when we talk about cognitive capitalism or the hegemony of immaterial labour, we do not refer to something 'immaterial' but to a very physical machinic intertwining of our own bodies and social relations.
} 
biopolítica. Em sua exposição sobre o que denomina "poder sobre a vida", uma oposição ao "direito de causar a morte e deixar viver" do poder soberano, Foucault, inicialmente, situa seus apontamentos em duas vertentes: a "anátomo-política do corpo" e a "bio-política da população". Uma espécie de biologização do trabalho pelo capital. Segundo ele:

[...] esse bio-poder, sem dúvida, foi elemento indispensável ao desenvolvimento do capitalismo, que só pode ser garantido à custa da inserção controlada dos corpos no aparelho de produção e por meio de um ajustamento dos fenômenos de população aos processos econômicos [...] (FOUCAULT, 1999 p. 132).

$\mathrm{Na}$ contemporaneidade, quando o capital realiza esse entrelaçamento entre corpo e relações sociais, ele na verdade está tomando a totalidade da vida como objeto de poder e isso inclui os aspectos subjetivos da mesma e não apenas o ideal marxista de força de trabalho (daí o cognitivo, e a defesa, em certos círculos, do termo capitalismo biopolítico). Independente, da nomenclatura utilizada, é inegável que tanto o trabalho imaterial quanto a própria ideia de capitalismo cognitivo são devedores desta vertente da filosofia política e, portanto, não seria errôneo afirmar que são biopolíticos. O capitalismo cognitivo lidaria, então, com a dimensão biopolítica do trabalho e, neste sentido, a obtenção da mais valia do trabalho operário requereria não só o esforço corporal, mas a aplicação da mente e das subjetividades nas dinâmicas de produção. De acordo com Pasquinelli:

[...] no início o capitalismo da era industrial explorava os corpos humanos por sua energia mecânica, mas rapidamente percebeu-se que a série de atos criativos, medições e decisões que os trabalhos precisam fazer constantemente são os valores mais importantes que eles produzem. [Romano] Alquati define como informação precisamente todas as micro-decisões inovativas que os trabalhadores precisam tomar ao longo do processo produtivo e que dão forma ao produto ao mesmo tempo que a seu aparato maquínico (PASQUINELLI, 2011, p. 07, grifos do autor e tradução nossa ${ }^{2}$ ).

Um conjunto de obras, constantemente associadas ao tema, a trilogia de Antonio Negri e Michael Hardt (Império, Multidão e Commonwealth) traz uma conceituação do que os autores denominaram produção biopolítica, que cabe perfeitamente à discussão da propriedade. Para os autores:

Todo aquele que trabalha com a informação ou o conhecimento - dos agricultores que desenvolvem propriedades específicas em determinadas sementes aos criadores

\footnotetext{
${ }^{2}$ Do original: At the beginning of the industrial age capitalism was exploiting human bodies for their mechanical energy, but soon it was realized that the series of creative acts, measurements and decisions that workers constantly have to take is the most important value that they produce. Alquati defines as information precisely all the innovative micro-decisions that workers have to take along the production process and that give form to the product but also give form to the machinic apparatus.
} 
de software - dependem do conhecimento comum recebido de outros e por sua vez criam novos conhecimentos comuns. Isto se aplica particularmente a todas as formas de trabalho que criam projetos imateriais, como ideias, imagens, afetos e relações. Daremos a este novo modelo dominante o nome de "produção biopolítica", para enfatizar que não só envolve a produção de bens materiais em sentido estritamente econômico como também afeta e produz todas as facetas da vida social, sejam econômicas, culturais ou políticas (NEGRI; HARDT, 2005 p. 14-15).

É justamente nesse caráter social intrínseco ao modo de produção contemporâneo que reside à queda (ou transmutação, como queiram) da noção de propriedade. Uma vez que o valor é coletivamente constituído, não é possível determinar a autoria de certo produto. Aliás, deve-se esquecer completamente essa qualificação reificadora de produto. O capitalismo cognitivo trata de processos, e como é da natureza dos mesmos, não há um fim, uma meta final (end goal), mas sempre uma dinâmica em aberto, cabendo sempre mais inputs, mais parceiros, mais pontos de vista, sejam eles peers ou investidores (o que, pela natureza do próprio termo, envolveria certa hierarquização). Por isso, os pensadores afirmam que:

À medida que o domínio impessoal do capital se estende por toda a sociedade, muito além das paredes da fábrica, e em termos geográficos por todo o planeta, o comando capitalista tende a tornar-se um "não-lugar", ou, na realidade, um todo lugar. Não existe mais um lado de fora do capital, nem tampouco um lado de fora da lógica do biopoder [...] esta correspondência não é uma coincidência, já que o capital e o biopoder funcionam intimamente juntos (NEGRI; HARDT, 2005, p. 142).

Isso é verdadeiro, tanto na criação e desenvolvimento descentralizados de um software livre pela colaboração de usuários anônimos na Internet e na "viralização" de um vídeo, gíria ou imaginário quanto no setor de serviços ou no modelo industrial de uma transnacional qualquer de produção em massa. Neste último, por exemplo, a mão de obra e a confecção são terceirizadas (de maneira global) - geralmente despachadas para países "em desenvolvimento" ou qualquer outro que ofereça a melhor relação custo-benefício - a matéria-prima é importada de uma terceira localidade, o maquinário de alta tecnologia é produzido nos grandes centros globais, o capital também é estrangeiro e de origem variada (uma vez no sistema financeiro, o dinheiro, simplesmente, "circula" deixando de ter um dono $^{3}$ ) e a administração obedece a uma matriz sediada num hipotético país de origem ou em escritórios ao redor do globo (hoje em dia, existem também empresas globais especializadas

\footnotetext{
${ }^{3}$ Esse reducionismo rudimentar foi feito apenas para fins de exemplificação, mas, sendo um pouco mais criterioso, poderia se dizer que a lógica do mercado financeiro demanda que o dinheiro, o capital, esteja sempre circulando, se movimentando de um lado para outro para que assim supostamente se gere a riqueza ou, como foi visto nos recentes casos de especulação, a crise. Neste sentido, é a flutuação do mercado que caracteriza o empreendimento e não a origem do (s) investidor (es) que pode (m) ser até anônimo (s).
} 
apenas em administrar outros negócios ${ }^{4}$ ).

Nesse universo de relativa instabilidade da indústria e do mercado, uma das mais importantes transições, para se ter em mente, é justamente a do emprego. Há um esvaziamento das esferas formais de trabalho, fazendo do capitalismo cognitivo a era da empregabilidade ao invés do emprego (COCCO, 2009). Uma situação análoga ao setor de serviços no qual muitas vezes se trabalha por "empreitada", projeto ou temporariamente. A chamada precarização do trabalho assalariado diz respeito a esse condicionamento por "demanda", não tendo garantidos jornada de trabalho fixa, tempo de lazer e estabilidade, enfim, direitos e "confortos" de nenhuma espécie. É preciso "se tornar flexível (realizar várias tarefas) e móvel (estar constantemente mudando de lugar)" (NEGRI; HARDT, 2005, p. 100).

Esse panorama está intimamente ligado à ampliação do escopo do capital, em que, como foi dito, a vida como um todo se torna objeto do poder. Portanto, o trabalho deixa de ser uma exclusividade da chamada "classe operária" que, em última análise, sempre significou o trabalhador assalariado (NEGRI; HARDT, 2005).

Quando essa noção se desfaz, percebe-se que os jovens, os desempregados, os subempregados (temporários e informais) e os consumidores de maneira geral (a outra “ponta" sempre negligenciada pelo marxismo mais "tradicional”) estão sujeitos ao capital e ao trabalho, pois com seus atos, renda, interesses, relações sociais etc. também contribuem para a produção do valor na contemporaneidade.

Seja ele representado pelo lucro monetário e demais ativos quantificáveis de uma empresa (tangível) ou no aumento de sua confiabilidade - um indicador tão prezado dos especialistas em marketing -, na produção e disseminação de conhecimento e na criação espontânea de remixes, spoofs e mashups promovendo a aculturação de um determinado conteúdo. Esse seria o trabalho na pós-modernidade que se desenvolveu como forma de “combater" as resistências ao modelo fabril iniciadas no final da década de 1960, sobretudo o emblemático ano de 1968. Essa resistência ao enquadramento das instituições (fábrica, escritório, escola, forças armadas, governo, casamento monogâmico etc.) que adentrou a década seguinte, pôs em movimento atos de contrainsurgência que resultaram, justamente, nesse paradigma do capitalismo contemporâneo de que tratamos.

\footnotetext{
${ }^{4}$ Em língua inglesa existem as siglas ASO e PEO que significam, respectivamente, Administrative Services Organization (Organização para Serviços Administrativos) e Professional Employer Organization (Organização Profissional de Empregadores). Sem entrar nos meandros técnicos, significa terceirizar o gerenciamento de uma empresa da mesma forma que se terceiriza a produção propriamente dita de uma fábrica. Embora o segundo termo de certa maneira seja mais genérico e englobe também o primeiro, esses "serviços" prestados entre empresas vão desde os já corriqueiros seleção e treinamento (os famosos headhunters) até consultorias financeiras, gestão de pessoal, de investimentos etc. Um exemplo seria o filme "Amor Sem Escalas" (Up in the air), de 2009, dirigido por Jason Reitman.
} 
Cenário esse, exposto por Negri e Hardt:

\begin{abstract}
Nas últimas décadas do século XX, o trabalho industrial perdeu sua hegemonia, surgindo em seu lugar o "trabalho imaterial", ou seja, o trabalho que cria produtos imateriais, como o conhecimento, a informação, a comunicação, uma relação ou uma reação emocional (NEGRI; HARDT, 2005, p. 149, grifo nosso).
\end{abstract}

Por sua vez, essa explosão do conceito de trabalho e sua "nova" abrangência, surgida justamente da necessidade de fazer produzir toda aquela efervescência cultural e recusa ao modelo industrial e disciplinar, fazem surgir formas de insubordinação, sendo a porta de entrada de subjetividades que não podem ser contidas dentro de nenhum sistema de exploração. De acordo com Negri e Hardt, "todas as formas de trabalho hoje em dia são socialmente produtivas, produzem em comum e também compartilham um potencial de resistir à dominação do capital. Podemos encarar essa realidade como uma igualdade de oportunidades de resistência" (2005, p. 147). E, acredita-se, essa resistência pode ser encontrada em dois conceitos similares ortograficamente, mas distintos semanticamente: common (o comum) e commons (o commons, uma oposição às commodities). Nessa diferenciação, reside a chave para compreender a pirataria e a produção por pares em seus modos particulares de estabelecer-se como diferença e, talvez, resistência.

Ambas abordam a questão de vieses distintos. Em nossa visão, enquanto os commons se ocupariam em tornar o mercado mais justo (e igualitário), permitindo assim uma integração com o mesmo, e, em certo sentido, abrindo caminho/espaço para modelos de negócios ${ }^{5}$, o comum se constitui como pura oposição, se apropriando, ocupando e interagindo livremente de acordo com uma ética própria (mas que, sem dúvida, está sujeita ao escrutínio moral, comercial e legal da sociedade).

A partir de 2007/8, a crise econômica que se acometeu sobre a economia global, cujo um dos marcos foi o rompimento da bolha imobiliária norte-americana, seguida por uma crise do crédito e, subsequente, quebra de instituições financeiras ao redor do mundo, pode indicar mudanças (ainda não vislumbradas em sua inteireza) não apenas marginais e de recusa, mas no centro dos métodos de produção. Nessa esteira, entende-se que a cultura hacker - e talvez, um devir-hacker - e a produção por pares estejam se consolidando como ethos e dinâmica deste "novo" momento. Por isso, por exemplo, diz-se que o:

"peer to peer é uma forma de relacionalidade entre seres humanos, pela quais pessoas podem se conectar umas com as outras sem permissão, e se reunir em torno

\footnotetext{
${ }^{5} \mathrm{O}$ que futuramente poderia ser questionado como mais uma espaço de exploração.
} 
da criação comum de valor ${ }^{6} "$ (BAUWENS et al, 2012, p. 158).

Neste texto, discutem-se exatamente quais as implicações dessas duas instâncias produtivas e sua agência sobre a ideia de propriedade.

\section{The commons and the common}

Reconhece-se que o que tem sido chamado até o presente momento de "singularidades" do P2P e da pirataria precisa ser melhor discutido. Para esta proposta, esta definição se encontra nas distintas esferas de atuação dos dois elementos selecionados. O P2P se configura como um modelo de compartilhamento, ou, sendo mais filosófico, um paradigma da colaboração e da estrutura em rede. Defendemos, assim, que ele serve como referencial econômico para este capitalismo pós-crise, no qual tanto a produção quanto o consumo já são intrinsecamente coletivos e tendem a se tornar, indissociavelmente, dependentes dessa colaboração como força-motriz. Supõe-se ainda que outras facetas deste movimento possam se desvelar, uma vez que cabe o questionamento se esse cenário levaria efetivamente a práticas (de mercado) mais democráticas ou mesmo se o mercado pode se tornar mais igualitário sem que isso signifique apenas uma interrupção paliativa do ciclo de exploração do capital.

Já a pirataria é mais conceitual e, por isso, multifacetada. Ela representaria, ao mesmo tempo, uma ideologia, uma estética, um fazer, um comércio (mesmo ilegal ou clandestino), entre inúmeras outras atribuições. Por esse motivo, visando não nos perdermos na polissemia do termo, declaramos que neste artigo a pirataria é tratada, em primeiro lugar, como prática e, em sua dimensão mais teórica (quando necessário) como um devir, uma multiplicidade em relação, seja com um devir revolucionário (DELEUZE, 2008) e/ou com um devir-Brasil do Mundo (COCCO, 2009). Castells (2003) a partir do pensamento de Steven Levy, por exemplo, define as atividades hackers como diferentes tipos de "programação criativa". Uma noção um tanto quanto genérica, uma vez que ele trata de hackers e não especificamente de piratas, mas, se consideramos o primeiro como um grupo majoritário que engloba o segundo, nos parece que esta definição seja ideal para as pretensões teórico-metodológicas deste estudo. Sob o ponto de vista político, acredita-se que esta busca por acessibilidade e uma demanda cultural dentro do capitalismo cognitivo poderiam representar uma ruptura dentro e contra o Império, proporcionando o surgimento de afetos ligados à capacitação cognitiva e

\footnotetext{
${ }^{6}$ Do original: Peer to peer is a form of relationality between human beings whereby people can connect to each other without permission, and aggregate around the creation of common value.
} 
"Peer piracy": aspectos centrais da produção por pares e da pirataria e suas contribuições nas transições do capitalismo

tecnológica. Nesse sentido, atividades hackers e/ou piratas estariam no cerne das práticas de compartilhamento que evidenciariam uma aliança entre o tecnológico, o político e o entretenimento.

Em nossa premissa, a mudança de paradigma criada pelo surgimento da cultura digital potencializou (e, claro, pluralizou) o surgimento de práticas inovadoras. E, encarando essas iniciativas como inovação - isso ainda sem considerar projetos específicos, mas tomando os termos por seu potencial de articulação -, observamos que em sua vertente digital, a que será considerada para este breve estudo, as duas vêm preenchendo espaços e atendendo a reivindicações que estão ligadas sempre a um movimento que busca uma maior liberdade ou liberação: de amarras comerciais e tecnológicas à própria luta contra a privação e a escassez. Entendendo ainda essas recusas e crises como endêmicas aos ciclos do capitalismo, Negri e Hardt resumem a questão da seguinte forma:

Cada nova forma de resistência destina-se a atacar as qualidades antidemocráticas das formas anteriores, criando uma cadeia de movimentos cada vez mais democráticos. [...] essa genealogia de guerras de libertação e movimentos de resistência permitir-nos-á identificar a forma mais adequada de organização para a resistência e as lutas de libertação na situação material e política contemporânea (NEGRI; HARDT, 2005, p. 103).

Aqui, evidencia-se a primeira das qualidades das duas temáticas tomadas como objeto, seu potencial organizacional, sobretudo no caso da produção por pares. Por sua descentralização e abertura a múltiplos referenciais e experiências, o P2P aparece como um dos delineadores dos possíveis rumos da sociedade em rede. Da mesma forma que anteriormente, na chamada Web 1.0, acreditava-se numa transposição do modelo de irradiação da chamada cultura de massa para a Internet - o que foi rechaçado pelas práticas dos usuários -, na Web 2.0, onde a participação é a regra, estaríamos presenciando uma fase em que não só esses usuários passam a opinar e influir diretamente no conteúdo veiculado, mas também, passam a produzir e distribuir seu próprio conteúdo por intermédio do maior acesso a ferramentas multimídia e a capacitação cognitiva no ambiente digital, formando toda uma (sub) cultura à parte do establishment e, o mais importante, sem necessariamente tomá-lo como referencial ${ }^{7}$. Para Bauwens et al:

Usuários agora podem não apenas responder e consumir pró-ativamente, ou compartilhar e produzir com suas redes, eles podem criar valor juntos enquanto

\footnotetext{
${ }^{7} \mathrm{O}$ recente canal humorístico Porta dos Fundos do Youtube não pode ser considerado uma iniciativa P2P, mas cabe nesse escopo maior de "produções feitas para a internet". Com um viés menos mercadológico, o Festival Home Theather através do site do evento, que serviu como plataforma de redistribuição, reuniu atores e diretores em residências espalhadas pelo Rio de Janeiro que serviram como palco para encenações teatrais.
} 
comunidades, se unindo em torno de objetos comuns. Esse é o mundo da produção por pares centrada nos commons expressa numa produção colaborativa de conhecimento (Wikipédia) e software $^{8}$ (BAUWENS et al, 2012, p. 23).

No âmbito do P2P, o crowdfunding, esse "financiamento pela multidão", surge como uma modalidade de arrecadação de recursos bastante popular no entretenimento atual. Ele trata da apresentação de um projeto - geralmente um produto cultural, um show, peça, filme, história em quadrinhos - que se realizará caso se angarie fundos suficientes num determinado período de tempo. Esse é um potente exemplo de entretenimento por demanda que tenta fazer com que os produtos culturais se tornem mais acessíveis ao mesmo tempo em que reestrutura a lógica do mercado 9 .

Dito isso, é necessário neste momento contemplar o cerne dessas questões, sua matriz política e cultural: as noções de comum e commons. Pensando o primeiro como uma expressão da subjetividade e das possibilidades materiais para uma recodificação (ou retomada) do caráter coletivo (múltiplo) e essencialmente compartilhado (acessível e livre) daquilo que existe, Negri e Hardt definem o comum como:

[...] a riqueza comum do mundo material - o ar, a água, os frutos do solo e todas as recompensas da natureza - o que na literatura europeia clássica é frequentemente tida como uma herança da humanidade como um todo, para ser compartilhada em conjunto. Nós consideramos o comum também e mais significativamente aqueles resultados da produção social que são necessariamente para interação social e produção continua, tais como conhecimento, linguagens, códigos, informação, afetos e assim por diante ${ }^{10}$ (NEGRI; HARDT, 2009, p. 8).

Os autores apresentam o comum como um amálgama, englobando elementos naturais e artificiais (produzidos) sob a ótica da interação e da partilha. Dentro dela o comum se torna um ponto de partida (e não um fim) para o desenrolar de trocas subjetivas nas quais se constroem relações sociais. Mais importante:

Essa noção do comum não separa a humanidade da natureza, seja como seu explorador ou guardião, mas antes foca nas práticas de interação, cuidado e coabitação num mundo comum, promovendo as formas benéficas e limitando as

\footnotetext{
${ }^{8}$ Do original: Users can not just pro-activitely consume and respond, or share and produce with their networks, they can create value together as communities, by coalescing around common objects. This is the world of commons-oriented peer production expressed in the collaborative production of knowledge (Wikipedia) and software.

${ }^{9}$ A cantora norte-americana Amanda Palmer é uma das recordistas em arrecadação até o momento, com US\$ 1,2 milhões, tendo custeado seu último álbum pelo processo. Além dela, o roteirista e diretor Charlie Kaufman e o projeto brasileiro Queremos também são considerados iniciativas de sucesso no meio.

${ }^{10}$ Do original: By "the common" we mean, first of all, the common wealth of the material world-the air, the water, the fruits of the soil, and all nature's bounty - which in classic European political texts is often claimed to be the inheritance of humanity as a whole, to be shared together. We consider the common also and more significantly those results of social production that are necessary for social interaction and further production, such as knowledges, languages, codes, information, affects, and so forth.
} 
"Peer piracy": aspectos centrais da produção por pares e da pirataria e suas contribuições nas transições do capitalismo

formas prejudiciais do comum ${ }^{11}$ (NEGRI; HARDT, 2009, p. 8).

Distancia-se, assim, da distinção dicotômica entre público e privado. Até porque, ambas estão intimamente ligadas a uma noção de pertencimento referenciada (ou garantida) seja pelo Estado ou pela iniciativa privada. Deste modo, não seria possível como acreditamos, substanciar as prática piratas e certo devir-hacker que necessariamente se proliferam no comum.

Por sua vez, os commons, quando aplicados ao mercado, tratam de uma economia baseada na desmonetarização e na criação de valor pelo uso coletivo. Os commons, em si, possuem uma definição bem similar àquela apresentada por Negri e Hardt sobre o comum. Segundo Bauwens et al:

Ligado a capacidade de cooperação global em torno de objetos de criação compartilhados está o conceito e a prática de um commons. Um commons é um recurso compartilhado que é herdado da natureza [...] ou criado por seres humanos, seja nos 'campos imateriais' do conhecimento e cultura (o que inclui, por exemplo, software livre e de código aberto e designs compartilhados) ou mantendo o capital humano produtivo (maquinário e meios de produção) em propriedade comum. $\mathrm{O}$ commons não é definido exclusivamente pela não propriedade e pelo acesso, mas por alguma forma de governança comum ${ }^{12}(2012$, p. 158).

Ainda que apresentem semelhanças, é possível ver que os conceitos se distanciam na medida em que trabalham com universos distintos, de certa forma até interconectados, mas intrinsecamente díspares. Negri e Hardt apresentam não um recurso ou um objeto, mas o comum como uma construção, por isso, eles falam de sua produção. Ou seja, esse é um comum no sentido de partilhado, mas principalmente no de não pertencimento. Dessa forma, os autores recorrem a uma explicação (bio) política do comum de maneira a transformá-la num espaço de lutas (para manter o comum comunitário ou para retomar esse aspecto depois de sua apropriação pelo capital), daí a necessidade do não pertencimento e a ideia de uma “produção do comum”, o que, para este artigo, poderia vir através das intervenções piratas. Neste sentido, os pensadores salientam que:

o que devemos reconhecer hoje [...] é uma noção de produção e da produtividade do comum que se estende igualmente do político ao econômico e a todos os terrenos da

\footnotetext{
${ }^{11}$ Do original: This notion of the common does not position humanity separate from nature, as either its exploiter or its custodian, but focuses rather on the practices of interaction, care, and cohabitation in a common world, promoting the beneficial and limiting the detrimental forms of the common.

${ }^{12}$ Do original: Linked to this capacity of global cooperation around shared objects of creation is the concept and practice of a commons. A commons is a shared resource that is either inherited from nature [...] or created by human beings, either in the 'immaterial fields' of knowledge and culture (this includes for instance free and open source software and shared designs), or by holding productive human capital (machinery and the means of production) in common stock. The commons is not exclusively defined by non-ownership and access, but by some form of common governance.
} 
produção biopolítica. A produtividade do comum, além disso, deve ser capaz de determinar não apenas a reforma dos corpos sociais existentes, mas sua radical transformação na carne produtiva da multidão (NEGRI; HARDT, 2005, p. 259).

Em contrapartida, como foi dito, o commons trata essencialmente de uma forma de gestão e acesso compartilhado (e racional) a um recurso ou bem. Esse caráter racional se deve às especificidades do recurso em questão que podem demandar algum tipo particular de "regramento" quanto ao seu acesso (ou até seu cerceamento puro e simples). Vale lembrar que a cultura digital e as questões autorais e intelectuais da qual tratam esse texto, se distanciariam das demandas organizacionais de bens físicos e, por conseguinte, finitos. O digital, por exemplo, possibilitaria, através de sua volatilidade, a conversão, transposição e cópia de conteúdo para diversos suportes e plataformas, o que, a priori, tornaria possível sua reprodução ilimitada e irrestrita sem perdas (de qualidade). Pensando também na questão de valor de uso contra valor de compra, a própria circulação de um determinado conteúdo, no caso de um produto, já seria uma forma de angariar fundos e prover sustento (ou lucro) ao responsável, ou responsáveis (produtor, artista, programador, colaboradores etc.). Como afirmam Bauwens et al:

na produção por pares baseada no comum, licenças livres/abertas garantem o uso compartilhado, modificação e uso de um commons de conhecimento, código ou design. Esses commons não são commodities em si que poderiam ser vendidas livremente no mercado, mas eles podem possibilitar mercados em produtos derivados e serviços ${ }^{13}$. (BAUWENS ET AL, 2012, p. 37).

Da mesma maneira que o comum não se trata de um produto em si (seja ele material ou imaterial), os commons são construções humanas e naturais que se desenvolvem com a própria partilha. É o fato de serem partilhados, a rede de ligações na qual eles são produzidos e consumidos, que faz seu valor e não uma ideia de autoria ou propriedade. Por não se tratar de uma questão inteiramente política, mas que não o deixa de ser em certo ponto, há de se considerar obviamente a questão da monetização e da propriedade.

Neste ponto se encontra a oposição do commons ao conceito de commodity. Enquanto esse seria a privatização de um recurso visando sua exploração comercial e exclusivista, gerando sempre uma escassez virtual - no sentido de "inventada", "produzida" e não de digital - como estratégia de mercado imanente ao sistema, os primeiros tratam da reorientação dessa ótica para a prática de um consumo mais inclusivo e, nesse sentido, mais democrático.

\footnotetext{
${ }^{13}$ Do original: In commons-based peer production free/open licenses guarantee the shared use, modification and use of a commons of knowledge, code and design. These commons are not themselves commodities that can easily be sold on the market place, but they can enable markets in derivative products and services.
} 
A cultura P2P, em si, trata da construção de subjetividades, liberdades e relações sociais, tanto quanto da edificação de um produto ou exploração (conjunta) de um recurso. Contudo, quando se fala em economias colaborativas e da utilização de um commons como forma de subsistência, isso não, necessariamente, significa sujeitar uma produção coletiva e livre ao capital. Apenas que, uma vez dentro do mesmo (já que não existe fora), seria possível, através da horizontalidade trazida por meio de práticas de produção e consumo colaborativas, criar alternativas com um potencial transformador dos aspectos econômicos, socioculturais e políticos do presente.

\section{CONSIDERAÇÕES FINAIS}

Tentando não se posicionar quanto a uma vertente ou outra, procurou-se mostrar como a pirataria e a produção por pares, podem ser entendidas, também, como "sintomas" de um momento de transição do capitalismo cognitivo pós-crise econômica mundial. Debatendo as contribuições individuais de cada uma para esse cenário, constatou-se que ambas trabalham a noção de propriedade de forma a conduzir a práticas mais democráticas e, em última instância, mais livres.

No que tange ao capitalismo cognitivo em si, viu-se que essas duas práticas são expressões da subjetividade, características da contemporaneidade e que, como tal, elas são o produto de ações de recusa de um modelo de sujeição da vida à produção. Pensando em questões mais prementes como a luta contra a privação e a escassez produzidas no seio do capitalismo, tentou-se argumentar que, embora de diretrizes até opostas, uma mais integradora e outra de pura oposição (e apropriação), o aspecto colaborativo de ambas faz com que se elas se constituam como maneiras efetivas de produção de diferença.

\section{REFERÊNCIAS}

BAUWENS, Michel; BURKE, James; IACOMELLA, Franco; MENDOZA, Nicolás. Synthetic overview of the Collaborative Economy. P2P Foundation, 2012.

CASTELLS, Manuel. A Galáxia Da Internet: reflexões sobre a internet, os negócios e a sociedade. Rio de Janeiro: Zahar, 2003.

COCCO, Giuseppe. MundoBraz: o devir-mundo do Brasil e o devir-Brasil do mundo. Rio de Janeiro: Record, 2009. 
DELEUZE, Gilles. Conversações. 7. reimp. São Paulo: Editora 34, 2008.

FOUCAULT, Michel. História Da Sexualidade I: a vontade de saber. 13. ed. Rio de Janeiro: Edições Graal, 1999.

NEGRI, Antonio e HARDT, Michael. Império. 9. ed. Rio de Janeiro: Record, 2010.

NEGRI, Antonio e HARDT, Michael. Multidão. Rio de Janeiro: Record, 2005.

NEGRI, Antonio; HARDT, Michael. Commonwealth. Cambridge: Harvard University Press, 2009.

PASQUINELLI, Matteo. Machinic Capitalism and Network Surplus Value: Notes on the Political Economy of the Turing Machine. 2011. Disponível em:

<http://matteopasquinelli.com/docs/Pa quinelli_Machinic_Capitalism.pdf >. Acesso em: 04 abr. 2012. 